\title{
Application of near infrared reflectance spectroscopy in screening of fresh cassava (Manihot esculenta crantz) storage roots for provitamin A carotenoids
}

\author{
E.O. Alamu, ${ }^{a, b}$ B. Maziya-Dixon, ${ }^{b *}$ T. Zum Felde, ${ }^{c}$ P. Kulakow ${ }^{a}$ and E. Parkes ${ }^{a}$ \\ ${ }^{a}$ Food and Nutrition Sciences Laboratory, International Institute of Tropical Agriculture (IITA) Southern Africa Hub, PO Box 310142, Chelstone, Lusaka, \\ Zambia \\ ${ }^{\text {bF }}$ ood and Nutrition Sciences Laboratory, International Institute of Tropical Agriculture (IITA), PMB 5320, Oyo Road, Ibadan, Oyo State, Nigeria. \\ E-mail: b.maziya-dixon@cgiar.org \\ International Potato Centre (CIP), Avenida La Molina 1895, La Molina Apartado Postal 1558, Lima, Peru
}

\begin{abstract}
A developed Near Infrared Reflectance Spectroscopy (NIRS) calibration equation was used for determining provitamin A carotenoids contents of different trials of fresh yellow root cassava genotypes using a total of 50 cassava genotypes scanned twice by NIRS from $400 \mathrm{~nm}$ to $2498 \mathrm{~nm}$. The NIRS calibration equations were used to predict the $\beta$-cryptoxanthin, 13-cis $\beta$-carotene, trans $\beta$-carotene, 9 -cis $\beta$-carotene, total $\beta$-carotene and total carotenoid concentrations of the samples. The predicted values for total carotenoids (TC-pred) ranged from $3.93 \mu \mathrm{gg}^{-1}$ to $10.51 \mu \mathrm{gg}^{-1}$ with mean of $7.07 \pm 2.55 \mu \mathrm{gg} \mathrm{g}^{-1}$ for International Collaborative Trials (ICT), 7.97-11.03 ${\mu g^{-1}}^{-1}$ fresh weight with mean of $9.40 \pm 0.76 \mu g^{-1}$ for yellow root trial 8 (Multi-location Uniform Yield Trial) and 6.38-10.44 $\mathrm{ugg}^{-1}$ with mean of $8.74 \pm 1.07{\mu g^{-1}}^{-1}$ for yellow root trial 9 (Multilocation Advanced Yield Trial). Total carotenoids results using refer-

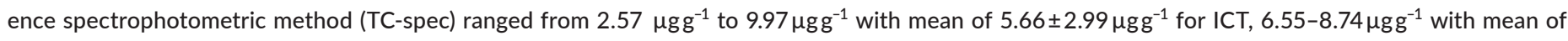
$7.74 \pm 0.64{\mu g^{-1}}^{-1}$ for yellow root trial 8 and $4.22-11.00 \mu g^{-1}$ with mean of $7.57 \pm 1.54 \mu g^{-1}$ for yellow root trail 9 . There is significant $(P \leq 0.001)$ positive correlation $(r=0.55)$ between TC-pred by NIRS and TC-spec. Also, significant $(P \leq 0.001)$ positive correlation $(r=0.52)$ exist between trans $\beta$-carotene predicted by NIRS and high-performance liquid chromatography reference. The developed NIRS calibration equations could be used to predict total carotenoids and trans $\beta$-carotene content of yellow root cassava and serve as rapid and cost-effective screening method for large cassava sample sets.
\end{abstract}

Keywords: Cassava, NIRS, trans $\beta$-carotene, $\beta$-cryptoxanthin, 13-cis $\beta$-carotene, 9-cis $\beta$-carotene

\section{Introduction}

Vitamin A deficiency is the most important cause of total blindness in developing countries. Micronutrient deficiencies including vitamin A afflict more than two billion individuals or one in three people globally. ${ }^{1}$ Enhancing the nutritional content of cassava through bio-fortification will have a significant, positive impact on nutrition status and overall health, especially for poorer communities where cassava is mainly consumed. Bio-fortification is complementary to other strategies for reducing malnutrition like supplementation, fortification and diversification; nutritional benefits come directly from the bio-fortified crops with no or little additional costs for consumers. Cassava roots have limited nutritional quality which has results for the large numbers of people, especially in sub-Saharan Africa, who depend on this staple to suffer from chronic vitamin A deficiency. ${ }^{2}$ To support bio-fortification programs there is a need for high

\section{Correspondence}

B. Maziya-Dixon (b.maziya-dixon@cgiar.org)

doi: 10.1255/nir2017.091

Citation: E.O. Alamu, B. Maziya-Dixon, T. Zum Felde, P. Kulakow and E. Parkes,

"Application of near infrared reflectance spectroscopy in screening of fresh cassava (Manihot esculenta crantz) storage roots for provitamin A carotenoids", in Proc. $18^{\text {th }}$ Int. Conf. Near Infrared Spectrosc., Ed by S.B. Engelsen, K.M. Sørensen and F. van den Berg. IM Publications Open, Chichester, pp. 91-97 (2019). https://doi.org/10.1255/nir2017.091

\section{(c) 2019 The Authors}

This licence permits you to use, share, copy and redistribute the paper in any medium or any format provided that a full citation to the original paper is given, the use is not for commercial purposes and the paper is not changed in any way.

ISBN: 978-1-906715-27-4 
throughput techniques to screen macro- and micronutrient concentrations of germplasm and breeding populations in tens of thousands of genotypes in short time frames. Near-infrared spectroscopy (NIRS) is currently used in large-scale nutritional quality analysis of many crops, ${ }^{3,4}$ as well as in carotenoids analysis in fresh cassava roots. ${ }^{5}$ The main advantages of the NIRS technique are high efficiency, low cost and simultaneous quantification of several traits in one measurement.

\section{Materials and methods}

50 freshly harvested improved pro-vitamin A cassava genotypes [which include genotypes from Multilocation Uniform Yield Trial (Yellow root 8), Multilocation Advanced Yield Trial (yellow root 9) and International Collaborative Trial (ICT)] were obtained from the experimental fields of International Institute of Tropical Agriculture (IITA) in Ibadan, Nigeria. Mature cassava roots were used, and the sampling method reported by Rodriguez-Amaya and
Mieko Kimura ${ }^{6}$ was employed with a selection of five roots sampled for each genotype. Three representative roots of the five were washed, air-dried, peeled and again washed and dried with soft paper. All sample preparations were done under dim lights in the laboratory. Each peeled root was cut longitudinally in half and the two halves were again cut longitudinally into quarters. Two opposite quarters of the three roots were pooled and cut in small pieces of about $1 \mathrm{~cm}^{3}$ and mixed together. A portion of the small pieces of root was taken as a representative of each genotype for the reference spectrophotometry method and NIRS analysis (Figure 1).

\section{NIRS analysis of fresh cassava samples}

About $10-15 \mathrm{~g}$ sample material of pieces of about $1 \mathrm{~cm}^{3}$ were scanned by NIRS twice using a coarse cell, spectral data were collected by measuring the diffuse
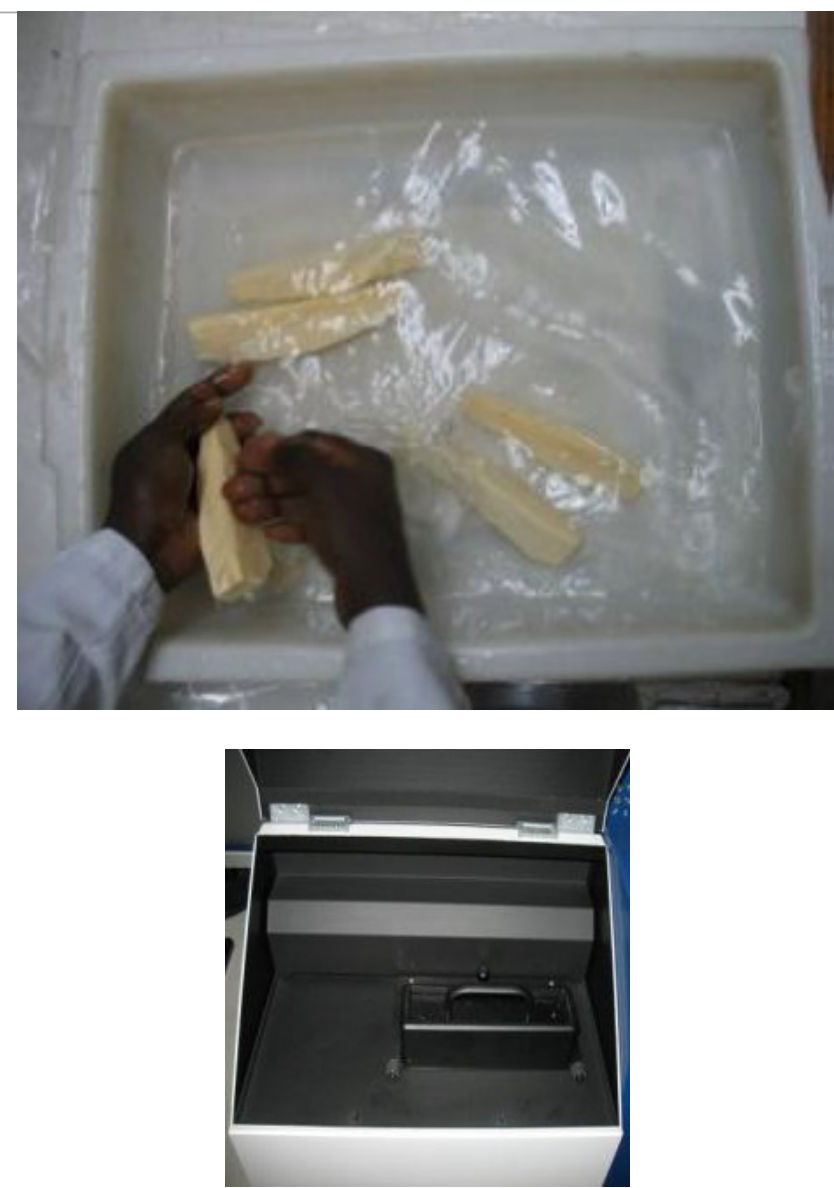

Figure 1. Sample preparation work flow of NIRS analysis in fresh cassava roots sample. 


\begin{tabular}{|c|c|c|c|c|c|c|c|c|c|c|c|c|c|c|c|}
\hline 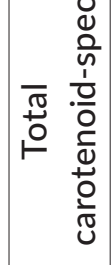 & in & $\begin{array}{l}0 \\
\sim \\
\infty\end{array}$ & \begin{tabular}{l}
$\infty$ \\
0 \\
0 \\
\multirow{1}{*}{}
\end{tabular} & $\begin{array}{l}\widetilde{N} \\
\text { ஸे }\end{array}$ & 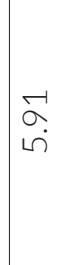 & $\begin{array}{l}n \\
\stackrel{n}{n} \\
\alpha\end{array}$ & $\hat{\alpha}$ & $\frac{\stackrel{N}{N}}{\stackrel{v}{v}}$ & $\begin{array}{l}\stackrel{\curvearrowright}{\sim} \\
\dot{m}\end{array}$ & $\begin{array}{c}0 \\
0 \\
i \\
i\end{array}$ & $\begin{array}{l}\hat{\alpha} \\
\dot{v}\end{array}$ & $\left|\begin{array}{c}\circ \\
\circ \\
-i\end{array}\right|$ & $\begin{array}{l}\underset{N}{N} \\
\text { N }\end{array}$ & & à. \\
\hline 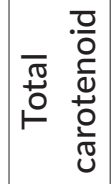 & $\begin{array}{l}\infty \\
2 \\
\dot{m}\end{array}$ & $\begin{array}{l}a \\
\sim \\
\alpha\end{array}$ & 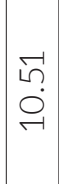 & 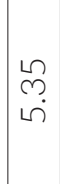 & $\begin{array}{l}\stackrel{\bigcirc}{+} \\
\stackrel{+}{*}\end{array}$ & 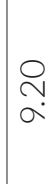 & $\stackrel{N}{\alpha}$ & 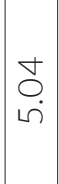 & $\begin{array}{l}0 \\
\text { లి } \\
0\end{array}$ & $\begin{array}{l}\hat{O} \\
\end{array}$ & $\stackrel{n}{\sim} \underset{\sim}{\sim}$ & $\mid \begin{array}{c}n \\
\infty \\
\infty \\
0\end{array}$ & $\begin{array}{l}\text { ○े } \\
\text { ळ. } \\
\text { ம் }\end{array}$ & & $\begin{array}{l}\text { in } \\
\text { On }\end{array}$ \\
\hline 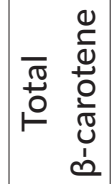 & $\begin{array}{l}\vec{J} \\
\dot{b} \\
\dot{m}\end{array}$ & \begin{tabular}{l}
0 \\
\multirow{1}{*}{} \\
$\infty$
\end{tabular} & 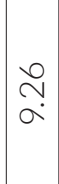 & 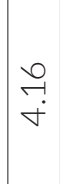 & $\begin{array}{l}\hat{n} \\
\text { m. }\end{array}$ & $\begin{array}{l}\Im \\
0 \\
\infty \\
\infty\end{array}$ & $\mid \begin{array}{l}1 \\
0 \\
0\end{array}$ & $\stackrel{\vec{\rho}}{\vec{\rho}}$ & $\begin{array}{l}\vec{b} \\
\dot{+}\end{array}$ & $\mid \begin{array}{l}\vec{N} \\
i r\end{array}$ & $\begin{array}{l}\stackrel{O}{+} \\
\stackrel{v}{v}\end{array}$ & $\left|\begin{array}{c}0 \\
\infty \\
0 \\
0\end{array}\right|$ & $\begin{array}{l}\hat{O} \\
\text { ํ. }\end{array}$ & & $\begin{array}{l}\stackrel{2}{2} \\
\alpha\end{array}$ \\
\hline 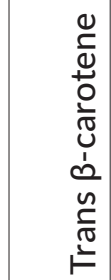 & $\begin{array}{r} \\
\infty \\
\infty \\
\stackrel{-}{-}\end{array}$ & $\begin{array}{l}\tilde{N} \\
+ \\
+\end{array}$ & $\begin{array}{l}\circ \\
\stackrel{0}{ } \\
\dot{+}\end{array}$ & $\begin{array}{l}a \\
\infty \\
-i\end{array}$ & $\begin{array}{l}\stackrel{P}{\stackrel{r}{r}} \\
\end{array}$ & $\begin{array}{l}\stackrel{\cap}{n} \\
\stackrel{\sim}{*}\end{array}$ & $\stackrel{\substack{\sim \\
\sim}}{\sim}$ & $\begin{array}{l}\curvearrowright \\
\stackrel{-}{r}\end{array}$ & $\begin{array}{l}\widetilde{O} \\
\stackrel{\sim}{N}\end{array}$ & $\begin{array}{l}\hat{\infty} \\
\dot{\sim} \\
\dot{v}\end{array}$ & $\begin{array}{l}\stackrel{\ominus}{ } \\
\text { ने }\end{array}$ & \begin{tabular}{l}
$\mathscr{m}$ \\
\multirow{\sigma}{*}{} \\
0
\end{tabular} & $\begin{array}{l}\vec{\forall} \\
\dot{f} \\
\dot{f}\end{array}$ & & $\begin{array}{l}\oslash \\
\triangleright \\
\dot{f}\end{array}$ \\
\hline 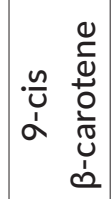 & $\begin{array}{l}n \\
\infty \\
0\end{array}$ & $\begin{array}{l}\infty \\
0 \\
0 \\
-\end{array}$ & $\begin{array}{l}\infty \\
\stackrel{\infty}{\sim}\end{array}$ & $\begin{array}{l}8 \\
\stackrel{0}{-}\end{array}$ & $\begin{array}{l}1 \\
\infty \\
\infty \\
0\end{array}$ & $\begin{array}{l}\stackrel{n}{n} \\
\stackrel{n}{-}\end{array}$ & 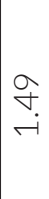 & $\begin{array}{l}a \\
0 \\
0\end{array}$ & $\begin{array}{l}\widetilde{O} \\
\stackrel{-}{-}\end{array}$ & $\begin{array}{c}\vec{N} \\
\vec{\sim}\end{array}$ & $\begin{array}{l}\stackrel{0}{+} \\
\stackrel{0}{0}\end{array}$ & $\mid \begin{array}{c}m \\
\overrightarrow{0} \\
\overrightarrow{0}\end{array}$ & 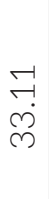 & & $\begin{array}{l}\infty \\
\stackrel{\sim}{\sim}\end{array}$ \\
\hline 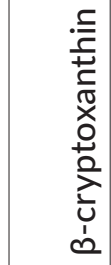 & $\frac{a}{2}$ & $\begin{array}{l}\tilde{N} \\
\stackrel{0}{0}\end{array}$ & $\begin{array}{l}m \\
m \\
0\end{array}$ & 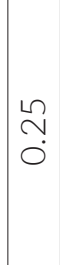 & $\stackrel{⿱}{\checkmark}$ & 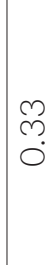 & ले & 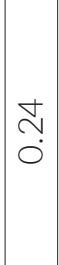 & 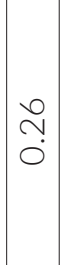 & $\begin{array}{c}\infty \\
N \\
0 \\
0\end{array}$ & $\begin{array}{l}\dot{J} \\
0 \\
\dot{0}\end{array}$ & $\begin{array}{c}-1 \\
0 \\
0\end{array}$ & $\begin{array}{l}\vec{n} \\
\dot{H} \\
\vec{H}\end{array}$ & & 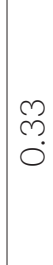 \\
\hline 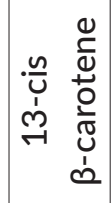 & $\frac{a}{2}$ & $\begin{array}{l}\infty \\
\infty \\
-i\end{array}$ & $\stackrel{\vec{I}}{\stackrel{\sim}{\sim}}$ & $\begin{array}{l}\stackrel{8}{0} \\
\stackrel{-}{-}\end{array}$ & $\begin{array}{l}0 \\
0 \\
0\end{array}$ & \begin{tabular}{l}
0 \\
0 \\
\hdashline
\end{tabular} & ن & $\stackrel{\stackrel{n}{f}}{\stackrel{0}{0}}$ & $\begin{array}{l}\circ \\
\vdots \\
0\end{array}$ & $\underset{\stackrel{\sim}{\sim}}{\stackrel{2}{\sim}}$ & $\begin{array}{l}\stackrel{0}{\text { ?n }} \\
\text { ó }\end{array}$ & 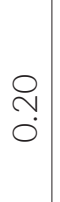 & $\begin{array}{l}\vec{t} \\
\text { o. } \\
\infty \\
+\end{array}$ & & $\underset{\sim}{\vec{i}}$ \\
\hline$\frac{\mathscr{O}}{\stackrel{0}{U}}$ & 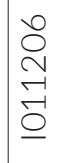 & $\begin{array}{l}\overrightarrow{\hat{N}} \\
\text { m} \\
\stackrel{-}{-} \\
\underline{0}\end{array}$ & 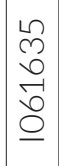 & $\begin{array}{l}\hat{n} \\
\hat{n} \\
0 \\
\hat{0} \\
\underline{0}\end{array}$ & $\begin{array}{l}\text { t } \\
\text { m } \\
0 \\
\hat{O} \\
\underline{0}\end{array}$ & 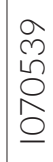 & $\begin{array}{l}m \\
2 \\
i \\
م \\
0 \\
0 \\
0\end{array}$ & $\begin{array}{l}\infty \\
\hat{n} \\
\stackrel{-}{\hat{\sigma}} \\
\underline{0}\end{array}$ & 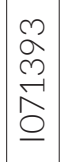 & 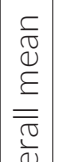 & $\dot{n}$ & $\dot{\omega}$ & $\vec{u}$ & $\stackrel{5}{\Sigma}$ & 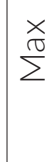 \\
\hline$\underset{⿱ 亠 䒑}{\vec{n}}$ & & & $m$ & $\nabla$ & $\llcorner\Omega$ & 0 & 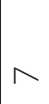 & $\infty$ & $a$ & & & & & & \\
\hline
\end{tabular}




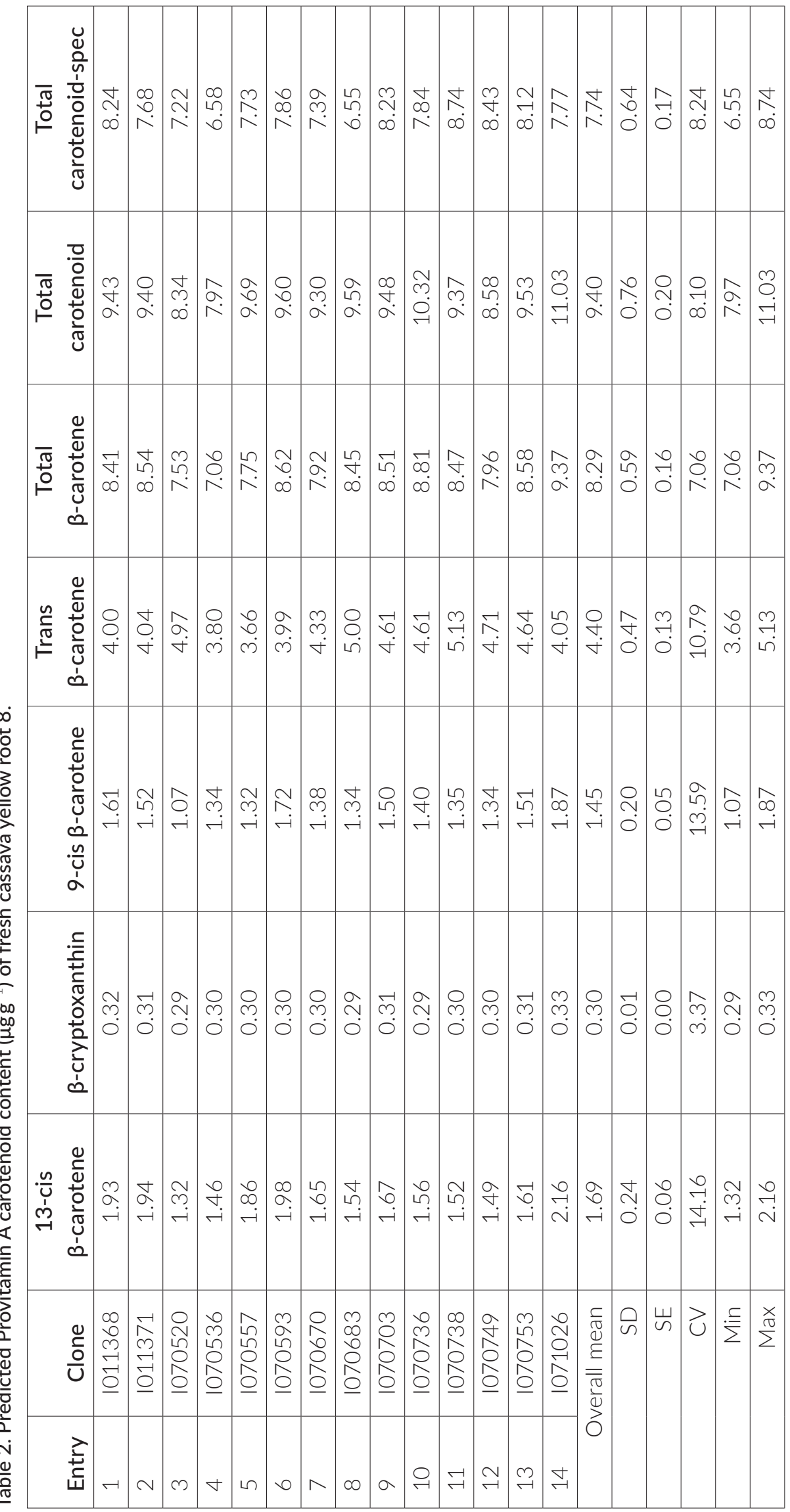




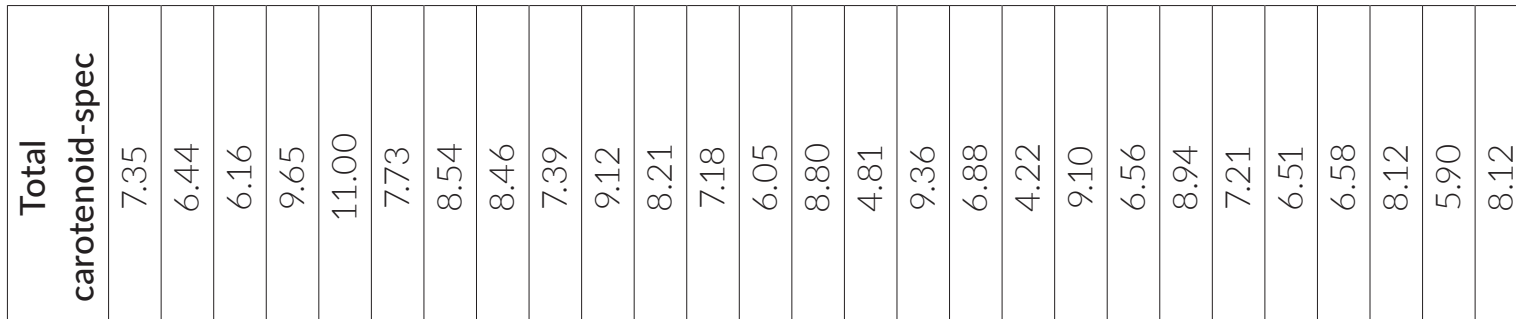

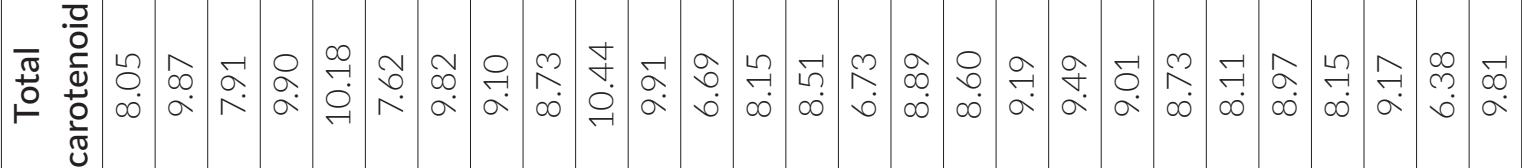

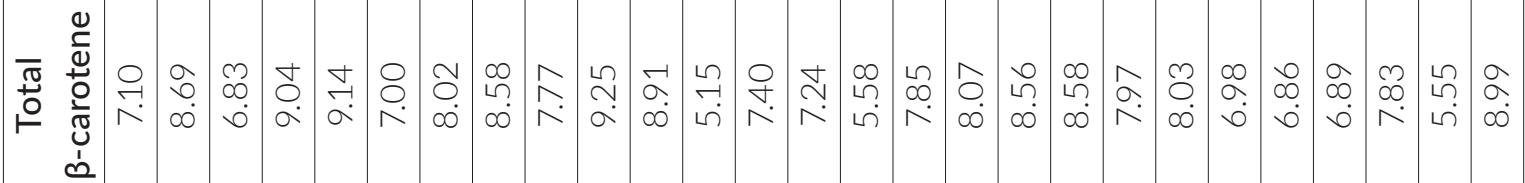

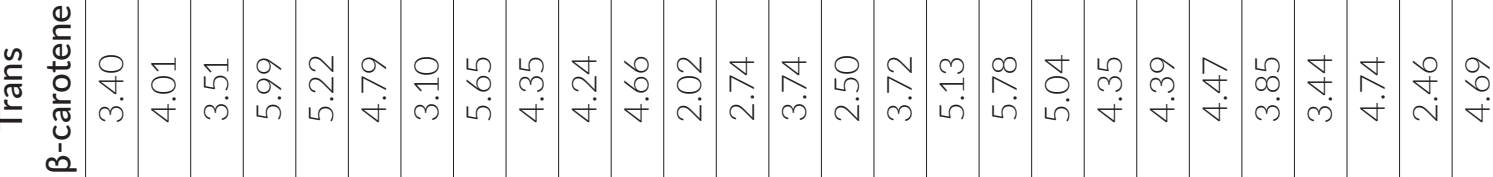
$\alpha$

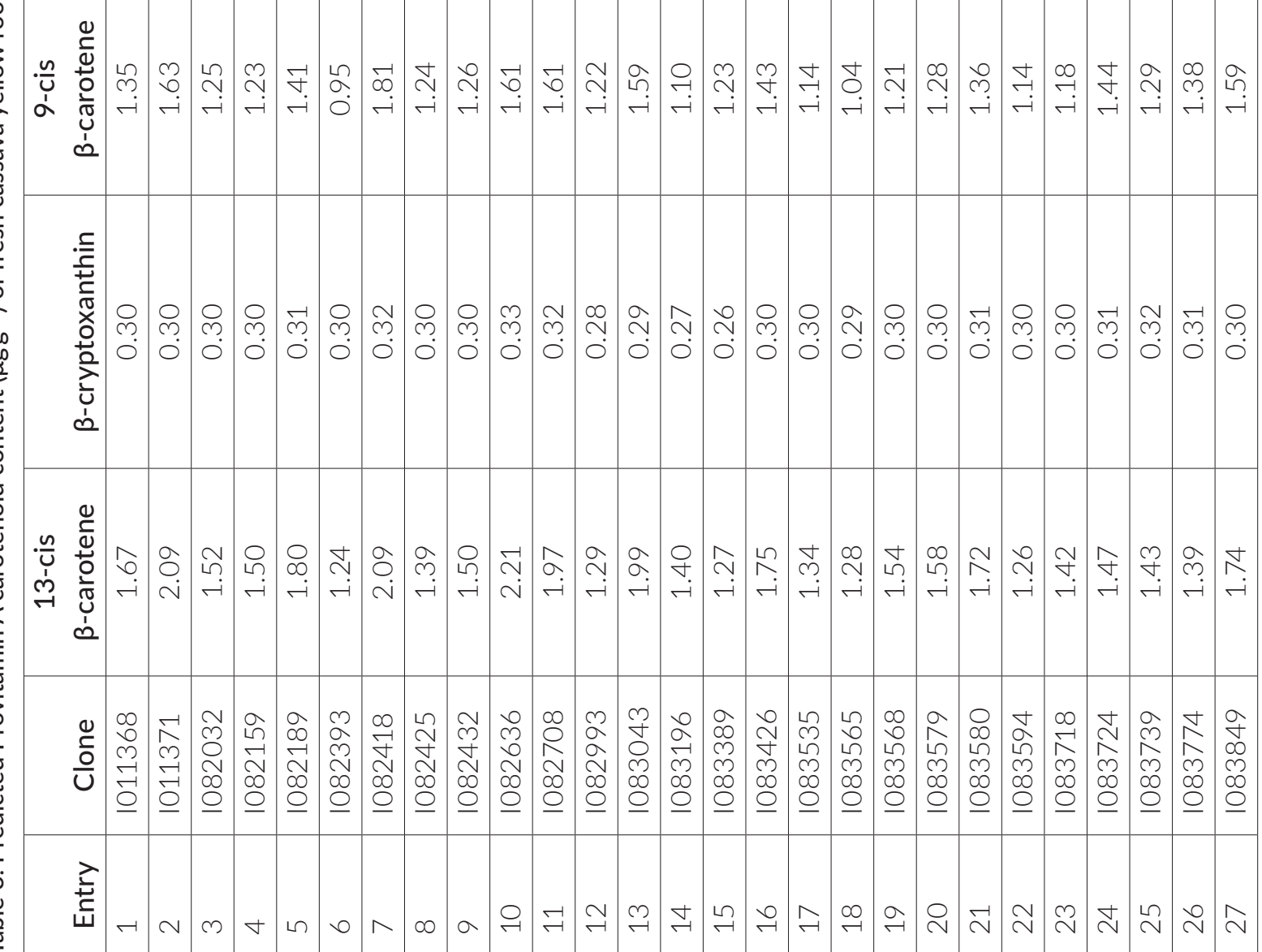




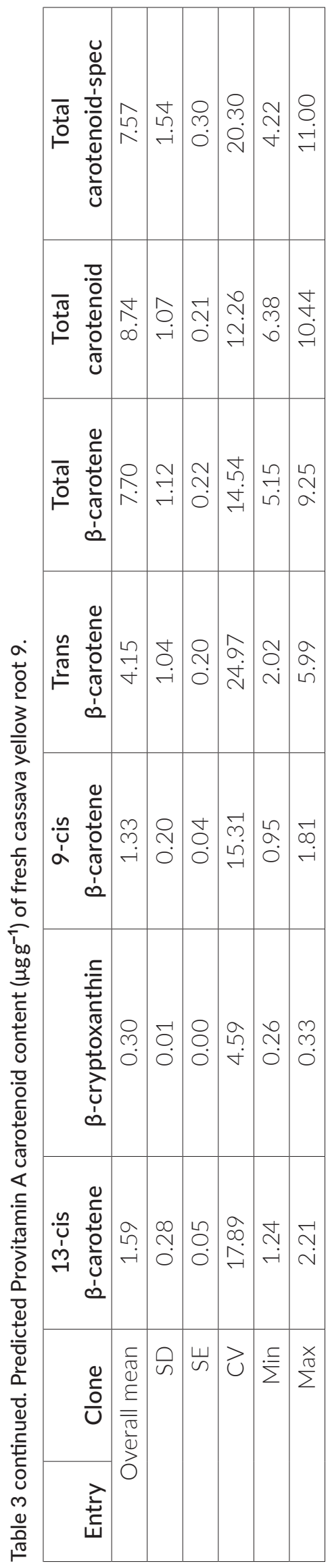

reflectance from the fresh roots in the NIR region within 400-2498 nm, using a NIRS monochromator (model FOSS XDS, solid module) and a coarse cell cup. Each sample was scanned in duplicate. The reflectance spectra were collected continuously over a NIR wavelength region with each spectrum represented as absorbance values $\log (1 / R)$ at $0.5 \mathrm{~nm}$ increments. The spectroscopic procedures and data recording were done using Win ISI software (Version 4.9.0; FOSS NIR Systems).

\section{Results and discussion}

The mean \pm standard deviations and ranges of the reference values and the statistics of the NIRS calibration and of the cross-validation are shown in Tables 1 and 2 respectively. The predicted values for total carotenoids (TC-pred) ranged from $3.93{\mu g^{-1}}^{-1}$ to $10.51 \mu^{-1} g^{-1}$ with mean of $7.07 \pm 2.55{\mu g^{-1}}^{-1}$ for ICT, 7.97-11.03 $\mu g^{-1}$ FW with mean of $9.40 \pm 0.76 \mu^{-1}$ g for yellow root trial 8 and $6.38-10.44{\mu g^{-1}}^{-1}$ with mean of $8.74 \pm 1.07{\mu g^{-1}}^{-1}$ for yellow root trial 9. Total carotenoid results using reference spectrophotometric method (TC-spec) ranged from $2.57 \mathrm{\mu g} \mathrm{g}^{-1}$ to $9.97 \mathrm{\mu g} \mathrm{g}^{-1}$ with mean of $5.66 \pm 2.99 \mathrm{ugg}^{-1}$ for ICT, 6.55-8.74 $\mathrm{gg} \mathrm{g}^{-1}$ with mean of $7.74 \pm 0.64 \mathrm{\mu g} \mathrm{g}^{-1}$ for yellow root trial 8 and $4.22-$ $11.00 \mathrm{\mu g} \mathrm{g}^{-1}$ with mean of $7.57 \pm 1.54 \mu^{g^{-1}}{ }^{-1}$ for yellow root 9. All trans $\beta$-carotene for ICT, yellow roots trials 8 and 9 ranged from $3.19{\mu g^{-1}}^{-1}$ to $9.26{\mu g^{-1}}^{-1} 7.06-$ $9.37 \mathrm{\mu g} \mathrm{g}^{-1}$ and $5.15-9.25 \mathrm{\mu g} \mathrm{g}^{-1}$ with an average of $5.71,8.29$ and $7.70 \mathrm{\mu g} \mathrm{g}^{-1}$ respectively. There is significant $(P<0.001)$ positive correlation $(r=0.55)$ between TC-pred by NIRS and TC-spec reference. Fresh ICT clone 1011206 has the least predicted Total carotenoids by NIRS and TC-spec, while clones 1061635 and 1070593 have the highest total carotenoids content predicted by NIRS and spectrophotometer respectively. Significant positive correlation also exists between trans $\beta$-carotene predicted by NIRS and that obtained from high-performance liquid chromatography reference (Table 4). Coefficient of variations for predicted total carotenoids by NIRS was $36.06 \%$ as compared to $52.72 \%$ observed from the reference TC-spec on fresh ICT cassava storage roots. The clones 1071026 have the highest predicted Total carotenoids of $11.03 \mathrm{\mu g} \mathrm{g}^{-1}$, while the least TC was obtained from clone 1070536 from yellow roots cassava 8. In contrast, TC-spec had the highest total carotenoids content $\left(8.74 \mu g^{-1}\right)$ from 
Table 4. Pearson correlation coefficients.

\begin{tabular}{|l|c|c|c|}
\hline Parameters & TC_spec & transBC(NIRS) & TC_(NIRS) \\
\hline TC_spec & 1 & $0.52^{* * *}$ & $0.55^{* * *}$ \\
\hline transBC(NIRS) & $0.55^{* * *}$ & 1 & $0.69^{* * *}$ \\
\hline TC_(NIRS) & $0.55^{* * *}$ & $0.69^{* * *}$ & 1 \\
\hline
\end{tabular}

*** Significant difference at $\mathrm{P}<0.001$

clone 1070738 and least value of $6.55 \mu g ~ g^{-1}$ from 1070683 (Table 2). For fresh cassava yellow roots 9 , the clone 1082636 had the highest total carotenoids content predicted by NIRS while the least content was seen from 1083774 respectively (Table 3), also TC-spec had the highest total carotenoids of $11.00 \mathrm{\mu g} \mathrm{g}^{-1}$ from clone 1082189 , while the least value of $4.22 \mathrm{\mu g} \mathrm{g}^{-1}$ was from the clone 1083565 respectively. The present study shows the reliability of the developed calibration equations to predict the total carotenoids and $\beta$-carotene content of fresh cassava roots as there were significant positive correlation between the predicted NIRS values and the reference values for each trait.

\section{Conclusion}

This study showed that the developed NIRS calibration equations can be used to predict total carotenoids and trans $\beta$-carotene content of yellow root cassava and serve as a rapid and cost-effective screening method for large cassava sample sizes from breeding programs. Since cassava breeders work with several thousands of breeding lines each year; application of NIRS for screening provide a useful tool for fast selection of promising cassava genotypes for further testing by HPLC.

\section{References}

1. FAO, IFAD, WFP, The State of Food Insecurity in the World 2015. FAO, Rome (2015).

2. G.Q. Lu and J.L. Sheng, "Application of near infrared reflectance spectroscopy (NIRS) in sweet potato quality breeding", Scientia Agricultura Sinica 23, 76-81 (1990).

3. S.K. Thakkar, B. Maziya-Dixon, A.G. Dixon and M.L. Failla, " $\beta$-carotene micellarization during in vitro digestion and uptake by $\mathrm{Caco}-2$ cells is directly proportional to $\beta$-carotene content in different genotypes of cassava", J. Nutrition 137, 2229-2233 (2007). https://doi.org/10.1093/jn/137.10.2229

4. J.G. Wu, C.H. Shi and X.M. Zhang, "Estimating the amino acid composition in milled rice by nearinfrared reflectance spectroscopy", Field Crops Res. 75(1), 1-7(2002). https://doi.org/10.1016/S03784290(02)00006-0

5. J.S. Bao, Y.Z. Cai and H. Corke, "Prediction of rice starch quality parameters of near-infrared reflectance spectroscopy", J. Food Sci. 66, 936-939 (2001). https://doi.org/10.1111/j.1365-2621.2001. tb08215.x

6. B.D. Rodriguez-Amaya and K. Mieko, Harvest Plus Handbook for Carotenoid Analysis. HarvestPlus Technical Monograph series 2 (2004). 